\title{
International Combination Service for Time-Variable Gravity Fields (COST-G)
}

\section{Start of Operational Phase and Future Perspectives}

\author{
Adrian Jäggi, Ulrich Meyer, Martin Lasser, Barbara Jenny, Teodolina Lopez, \\ Frank Flechtner, Christoph Dahle, Christoph Förste, Torsten Mayer-Gürr, \\ Andreas Kvas, Jean-Michel Lemoine, Stéphane Bourgogne, \\ Matthias Weigelt, and Andreas Groh
}

\begin{abstract}
The International Combination Service for Time-variable Gravity Fields (COST-G) is a new Product Center of IAG's International Gravity Field Service (IGFS). COST-G provides consolidated monthly global gravity fields in terms of spherical harmonic coefficients and thereof derived grids of surface mass changes by combining existing solutions or normal equations from COST-G analysis centers (ACs) and partner analysis centers (PCs). The COST-G ACs adopt different analysis methods but apply agreed-upon consistent processing standards to deliver time-variable gravity field models, e.g. from GRACE/GRACE-FO lowlow satellite-to-satellite tracking (1l-SST), GPS high-low satellite-to-satellite tracking (hlSST) and Satellite Laser Ranging (SLR). The organizational structure of COST-G and results from the first release of combined monthly GRACE solutions covering the entire GRACE time period are discussed in this article. It is shown that by combining solutions and normal equations from different sources COST-G is taking advantage of the statistical properties of the various solutions, which results in a reduced noise level compared to the individual input solutions.
\end{abstract}

\section{Keywords}

Combined solutions $\cdot$ COST-G $\cdot$ IGFS Product Center $\cdot$ Time variable gravity

A. Jäggi $(\bowtie) \cdot$ U. Meyer · M. Lasser · B. Jenny · T. Lopez Astronomical Institute, University of Bern, Bern, Switzerland e-mail: adrian.jaeggi@aiub.unibe.ch

F. Flechtner · C. Dahle $\cdot$ C. Förste

GFZ German Research Centre for Geosciences, Potsdam, Germany

T. Mayer-Gürr · A. Kvas

Institute of Geodesy, Technical University of Graz, Graz, Austria

J.-M. Lemoine

Department of Terrestrial and Planetary Geodesy, Centre National d'Etudes Spatiales, Toulouse, France

S. Bourgogne

Stellar Space Studies, Esplanade Compans Caffarelli, Toulouse, France

M. Weigelt

Institut für Erdmessung, University of Hannover, Hannover, Germany

\section{Introduction}

Ultra-precise inter-satellite ranging as performed for more than 15 years by the GRACE mission has been established as the state-of-the-art technique to globally observe mass variations in the system Earth from space (Tapley et al. 2019). Continued meanwhile by its Follow-On mission (GRACEFO, Flechtner et al. 2013), a growing number of institutions is processing the GRACE/GRACE-FO Level-1B instrument data to derive mass variations on a monthly basis (Level-2

\footnotetext{
A. Groh

Institut für Planetare Geodäsie, Technische Universität Dresden, Dresden, Germany
} 
products). Although each new release of monthly gravity fields represents a significant improvement with respect to earlier releases, the solutions of different institutions usually differ considerably in terms of noise (Jean et al. 2018) and sometimes also in terms of signal (Meyer et al. 2015). In the frame of the European Gravity Service for Improved Emergency Management (EGSIEM) initiative, a prototype of a scientific combination service has been set up to demonstrate that improved solutions may be derived by combining individual solutions which are based on different approaches but agreed-upon processing standards (Jäggi et al. 2019). The Combination Service of Time-variable Gravity Fields (COST-G) continues the activities of the scientific combination prototype service of the EGSIEM initiative to realize a long-awaited standardization of gravityderived mass transport products under the umbrella of the International Association of Geodesy (IAG). Established at the 2019 General Assembly of the International Union of Geodesy and Geophysics (IUGG) as a new Product Center of IAG's International Gravity Field Service (IGFS) for timevariable gravity fields, COST-G will operationally provide consolidated monthly global gravity models with improved quality, robustness, and reliability both in terms of spherical harmonic $(\mathrm{SH})$ coefficients and thereof derived grids of surface mass changes by combining solutions or normal equations (NEQs) from COST-G analysis centers (ACs). The COST-G ACs are adopting different analysis methods but apply agreed-upon consistent processing standards ${ }^{1}$ to deliver time-variable gravity field models, e.g. from GRACE or GRACE-FO low-low satellite-to-satellite tracking (11SST) or from non-dedicated data such as GPS high-low satellite-to-satellite tracking (hl-SST) or Satellite Laser Ranging (SLR). In addition COST-G makes use of existing and publicly available solutions or NEQs of Partner Analysis Centers (PCs), who are directly linked with the GRACE and GRACE-Follow On project. PCs are producing quality controlled products following their own project requirements which may not necessarily be in compliance with the COSTG standards.

The article is structured as follows: Sect. 2 provides an overview of the COST-G organization, Sect. 3 describes the COST-G workflow by discussing the first release of COST-G GRACE Level-2 products and Sect. 4 concludes the article with a summary and future perspectives.

\section{COST-G Organization}

COST-G is organized in close analogy to other IAG services (Drewes et al. 2016). It is steered by a Directing Board, which sets the objectives and the scientific and operational

\footnotetext{
${ }^{1}$ https://cost-g.org/download/COST_G_STANDARDS.pdf.
}

goals. The COST-G objectives to derive time-variable gravity fields with improved quality, robustness, and reliability are accomplished by the following components.

\subsection{Central Bureau (CB)}

The Central Bureau is responsible for all operational activities of the Service. The Central Bureau coordinates COST$\mathrm{G}$ activities, facilitates communications and maintains documentations. The CB is currently located at the Astronomical Institute of the University of Bern (AIUB).

\subsection{Analysis Centers (ACs)}

The COST-G Analysis Centers produce time-variable gravity field solutions according to the specifications defined by the COST-G Processing Standards defined by the COST-G Directing Board. For the analysis of GRACE/GRACE-FO data the current $\mathrm{ACs}$ are, in alphabetical order:

- Astronomical Institute, University of Bern (AIUB)

- Centre National d'Etudes Spatiales (CNES/GRGS)

- German Research Centre for Geosciences (GFZ)

- Institute of Geodesy, Graz University of Technology (IfG/ITSG)

The list of ACs may differ for the processing of nondedicated satellite data to derive alternative monthly solutions of the Earth's time-variable gravity field, e.g. from Swarm hl-SST data in the frame of an ESA initiative (Teixeira da Encarnação et al. 2019).

The ACs send their solutions to the Analysis Center Coordinator for combination together with a summary describing their processing strategy. Depending on the availability of new or improved AC contributions, new combined solutions are released. GRACE contributions need to cover at least the time period 2003 to mid 2016 to be included in the combination. Shorter periods may be considered for testing. Corresponding rules for GRACE-FO, hl-SST, SLR contributions will be defined when a significantly large number of ACs is available and has consolidated their processing strategies.

\subsection{Partner Analysis Centers (PCs)}

COST-G will in addition make use of existing and publicly available solutions or NEQs of other processing centers, denoted as Partner Analysis Centers (PC). Currently, these are primarily centers that are part of the GRACE and GRACE-FO project, e.g. the Center for Space Research (CSR) of the University of Texas at Austin or NASA's Jet Propulsion Laboratory (JPL), who are producing quality 
controlled products following their own project requirements. COST-G retains the right to exclude solutions if they either deviate from the COST-G Processing Standards or do not comply with decisions of the COST-G Directing Board.

\subsection{Analysis Center Coordinator (ACC)}

The Analysis Center Coordinator, currently located at AIUB, first compares the individual gravity fields for quality control. From the comparison of the solutions passing the quality control the ACC defines empirical weights for the individual contributions. Eventually, he combines the accepted solutions to generate a combined gravity field using the underlying normal equations of the individual ACs (Meyer et al. 2019). If normal equations are not available, combinations may also be performed on the solution level (Jean et al. 2018). The resulting COST-G solutions (Level-2 products) are published at the International Center for Global Earth Models (ICGEM, Ince et al. 2019).

\subsection{Validation Center (VC)}

Validation of the COST-G products happens at the Validation Center, which is currently operated by the COST-G ACs at CNES and GFZ. This involves the evaluation of the noise of the solutions over dedicated areas of low variability, as well as the evaluation of the solution quality through comparison with external data from altimetry. Eventually the COST-G products are also validated through fits of tracking data of Low Earth Orbiters.

\subsection{Product Evaluation Group (PEG)}

External expert users not associated with COST-G ACs are forming the COST-G Product Evaluation Group. They assess the COST-G products for studying mass variations related to terrestrial water storage over non-glaciated regions, bottom pressure variations in the oceans and ice mass changes in Antarctica and in Greenland.

\subsection{Level-3 Product Center (L3C)}

Various corrections and reductions have to be applied to the Level-2 products, resulting in post-processed $\mathrm{SH}$ coefficients (Level-2B products), before user-friendly Level-3 products are generated by the Level-3 Product Center, currently located at GFZ. The COST-G Level-3 products are visualized and described at GFZ's Gravity
Information Service (GravIS, http://gravis.gfz-potsdam. de) and will be made available by GFZ's Information System and Data Center (ISDC, https://isdc.gfz-potsdam. de). Additionally, the products can also be visualized at the COST-G Plotter (http://cost-g.org/).

\section{COST-G Workflow}

The workflow of COST-G is illustrated by Fig. 1. It consists of harmonization and quality control of the individual input solution of the different ACs and PCs, and the combination and validation of the resulting COST-G solution. All aspects of this process are explained and illustrated in more detail in the subsequent subsections by discussing the results of the first release of combined GRACE Level-2 products (GRAC_COSTG_BF01_0100, subsequently addressed as COST-G RL01).

\subsection{Harmonization of Input Solutions}

The individual input solutions of the different ACs may differ in the underlying constants (Earth's gravity constant, Earth's equatorial radius), tide system, and mean pole convention (see Eq. 21 in Wahr et al. (2015)). Individual solutions may thus need to be re-scaled and individual coefficients $\left(C_{20}, C_{21}, S_{21}\right)$ may need to be further corrected to be compliant with the tide system and mean pole convention used by COST-G. Additional background models, such as the atmosphere and ocean dealiasing product (AOD), may also differ between groups and are consolidated before the combination to ensure a consistent signal definition.

\subsection{Quality Control of Input Solutions}

For quality control of the COST-G products, the signal and noise content of the harmonized $\mathrm{AC}$ contributions are first compared. The signal content is analyzed by computing the amplitude of seasonal variations of equivalent water height $(\mathrm{EWH})$ for a large number of river basins and by computing ice mass trends in Greenland and Antarctica. An assessment of the noise is performed by analyzing anomalies, which represent the monthly variability after subtraction of a deterministic model of secular and seasonal variations. The assessment of the seasonal variations of the input solutions for COST-G RL01 is discussed below, whereas the assessment of ice mass trends will be separately discussed in Sect. 3.4.1. The noise assessment is not reproduced here as it largely corresponds to earlier results presented in Jean et al. (2018) and Meyer et al. (2019). 


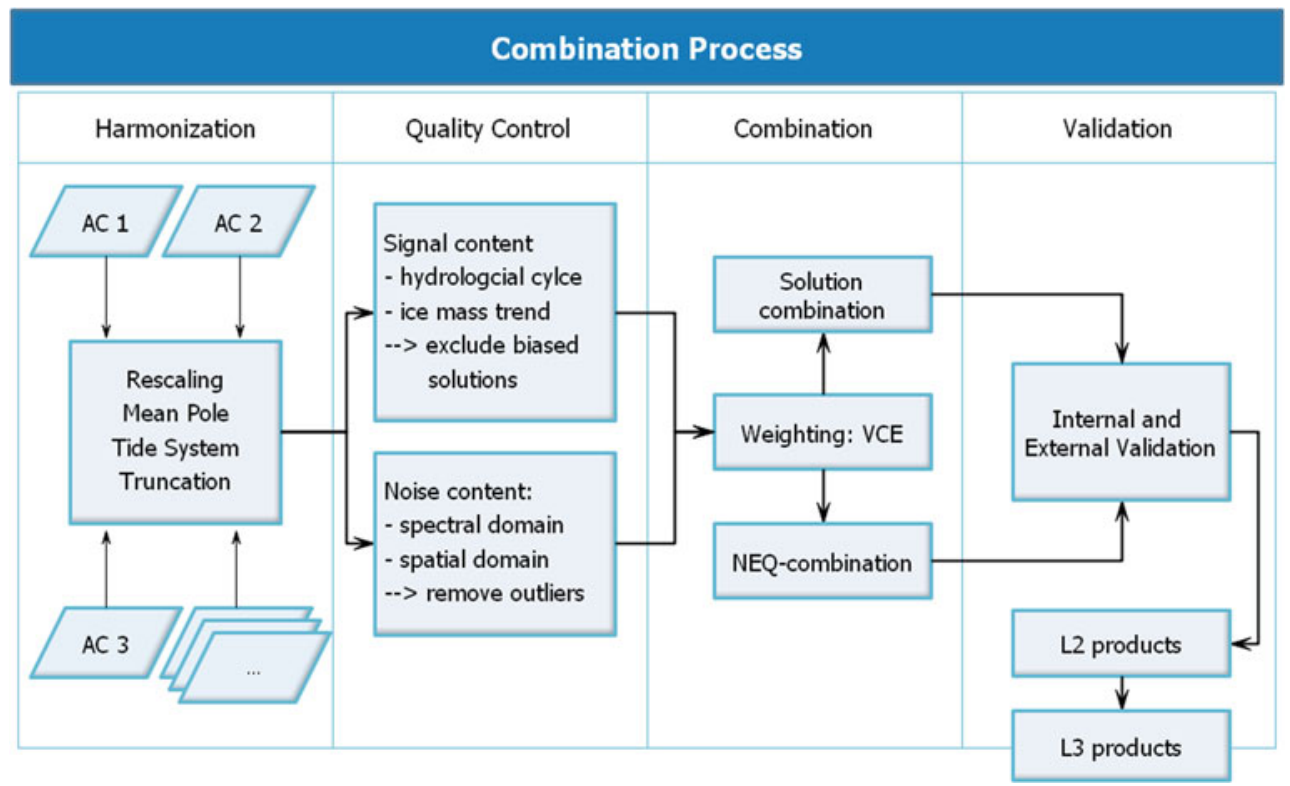

Fig. 1 COST-G workflow
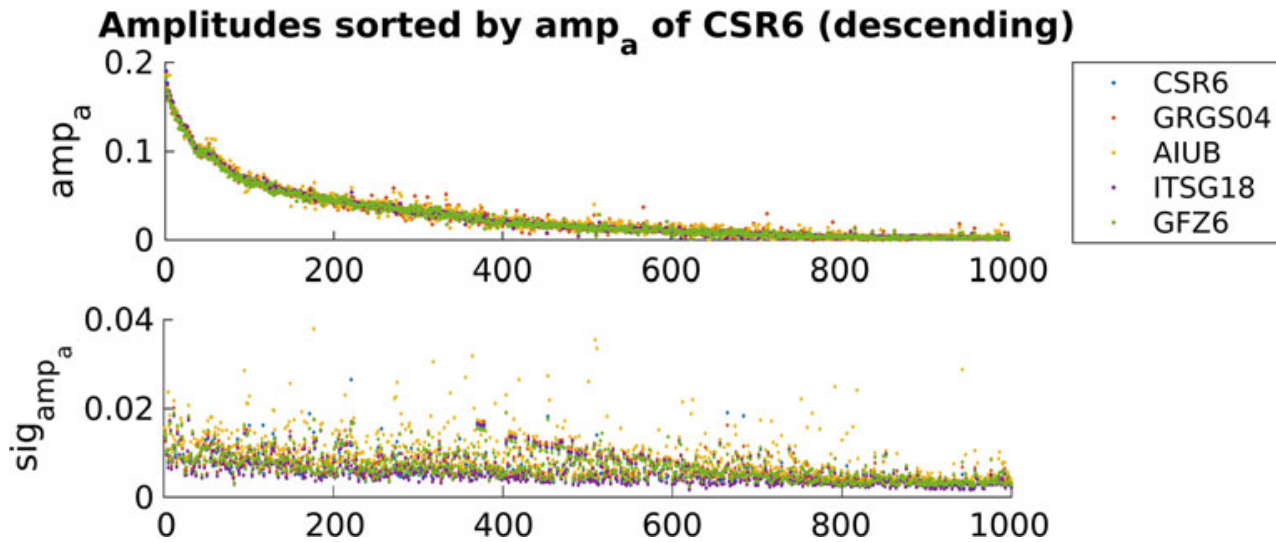

Fig. 2 Amplitude of seasonal variations (top) and formal errors of amplitudes (bottom) in MEWH (m) for major river basins using a $400 \mathrm{~km}$ Gauss filter

Figure 2 (top) shows the amplitudes, expressed in mean equivalent water height (MEWH), of the estimated seasonal variations for the 500 largest river basins as derived from all $\mathrm{AC}$ and PC solutions used for the COST-G RL01. The underlying river basin masks were taken from the Total Runoff Integrating Pathways (TRIP4 ${ }^{2}$ ) model. The corresponding formal errors of the estimation are shown in Fig. 2 (bottom). The analysis shows that no systematic signal attenuation may be observed for seasonal signals in any of the contributing gravity field time-series. The cluster of outlying larger formal errors visible in Fig. 2 (bottom) is related to regions with small seasonal signals and large non-linear trends as occurring, e.g. for regions with accelerated ice mass loss.

\footnotetext{
${ }^{2}$ http://hydro.iis.u-tokyo.ac.jp/ taikan/TRIPDATA/TRIPDATA.html.
}

\subsection{Combination of Input Solutions}

Generally, the planned strategy for future COST-G releases is to provide a combination based on the underlying NEQs of the individual ACs according to the methodology presented in Meyer et al. (2019). As NEQs were not available from all centers, the combination was performed on the solution level for the COST-G RL01 as a weighted combination of the SH coefficients using variance component estimation (VCE) (Jean et al. 2018). The underlying AC und PC solutions are, AIUB RL02 (Meyer et al. 2016), GRGS RL04, GFZ RL06 (Dahle et al. 2019), ITSG-Grace2018 (Kvas et al. 2019), and CSR RL06 (Save et al. 2018).

Apart from AIUB RL02, which is still based on the RL02 of the GRACE Level-1B data, all input solutions are based on 
Fig. 3 Weights assigned to input solutions

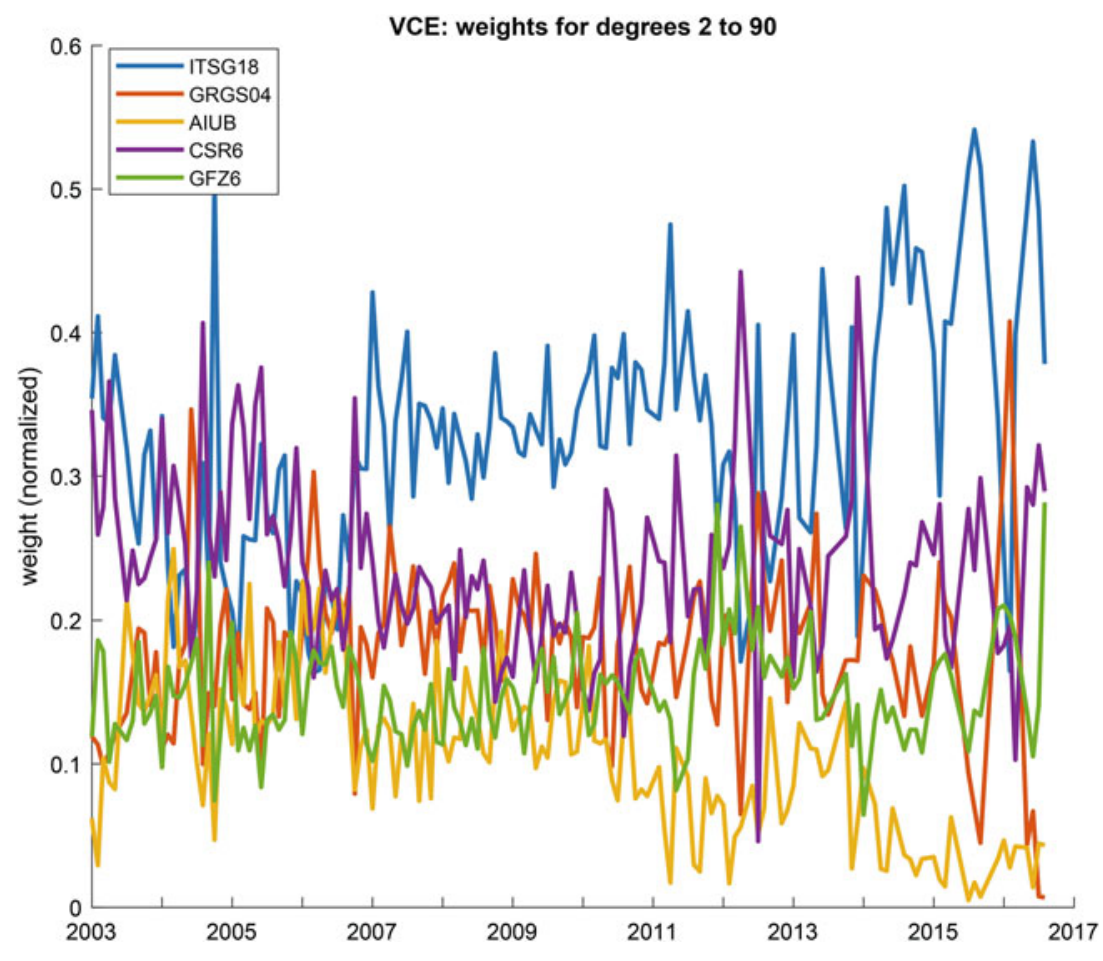

the most recent RL03 of the GRACE Level-1B data (GRACE Level 1B JPL Release 3.0 2018). For the GRGS solution the underlying NEQs were inverted by the ACC to obtain a solution without regularization.

Figure 3 shows the relative weights assigned to the individual input solutions as determined by VCE. The weights can be interpreted as quality indicators of the solutions as they are inversely proportional to the noise levels of the individual contributions. The highest weights are usually assigned to the ITSG-Grace2018 solutions due to their very low noise level. This is largely related to the sophisticated empirical noise modeling of the ITSG-Grace2018 solution (Kvas et al. 2019) and in accordance with analyses based on earlier ITSG releases (Jean et al. 2018). Lowest weights are usually assigned to the AIUB RL02 solutions due to the use of (meanwhile) outdated Level-1B data and, in particular, since active thermal control of the GRACE satellites was switched off in April 2011 (Tapley et al. 2015), which would have required adaptions in the accelerometer parametrization as shown in Klinger and Mayer-Gürr (2016).

Figure 4 shows median degree amplitudes of anomalies for the combined solution as well as for the input solutions that contributed to the combination for the entire GRACE time period with respect to a linear and seasonal model without applying any filtering. The analysis reveals that in the spectral domain the main gain of the combination is in the range of degrees 15-45. When truncating all gravity fields at order 29 to exclude the effect of the noisy higher-order $\mathrm{SH}$ coefficients, which are usually attenuated in applications by post-processing filters, e.g. Kusche (2007), the gain of the combination may even be seen up to about degree 65 . The lower noise of the combined solution may also be confirmed in the spatial domain by analyzing the RMS of EWH anomalies over the oceans (not shown).

\subsection{Validation of Combined Solution}

Internal and external validation is performed to ensure the quality of the COST-G solutions by identifying outlying or systematically deviating input solutions.

\subsubsection{Internal Validation}

Ice mass loss in the polar regions is of enormous societal relevance (Shepherd et al. 2012). Evaluating GRACE mass change time series for the ice sheets in Antarctica and Greenland, as derived from the individual input solutions and the combined COST-G solution, is thus an essential task of the COST-G product evaluation group to detect potential inconsistencies between the input solutions.

\section{Greenland Ice Sheet}

GRACE-derived mass change time series are derived from all input solutions that contributed to the combination for the entire GRACE time period and from the combined COST$\mathrm{G}$ solution for all drainage basins of the Greenland Ice Sheet $\left(\mathrm{GIS}^{3}\right)$ and for the entire Greenland Ice Sheet by adopting the

${ }^{3}$ http://icesat4.gsfc.nasa.gov/cryo_data/ant_grn_drainage_systems.php. 
Fig. 4 Median degree amplitudes of residual $\mathrm{SH}$ coefficients. Solid: full spectrum, dashed: limited to order $\mathrm{m}=0 \ldots 29$

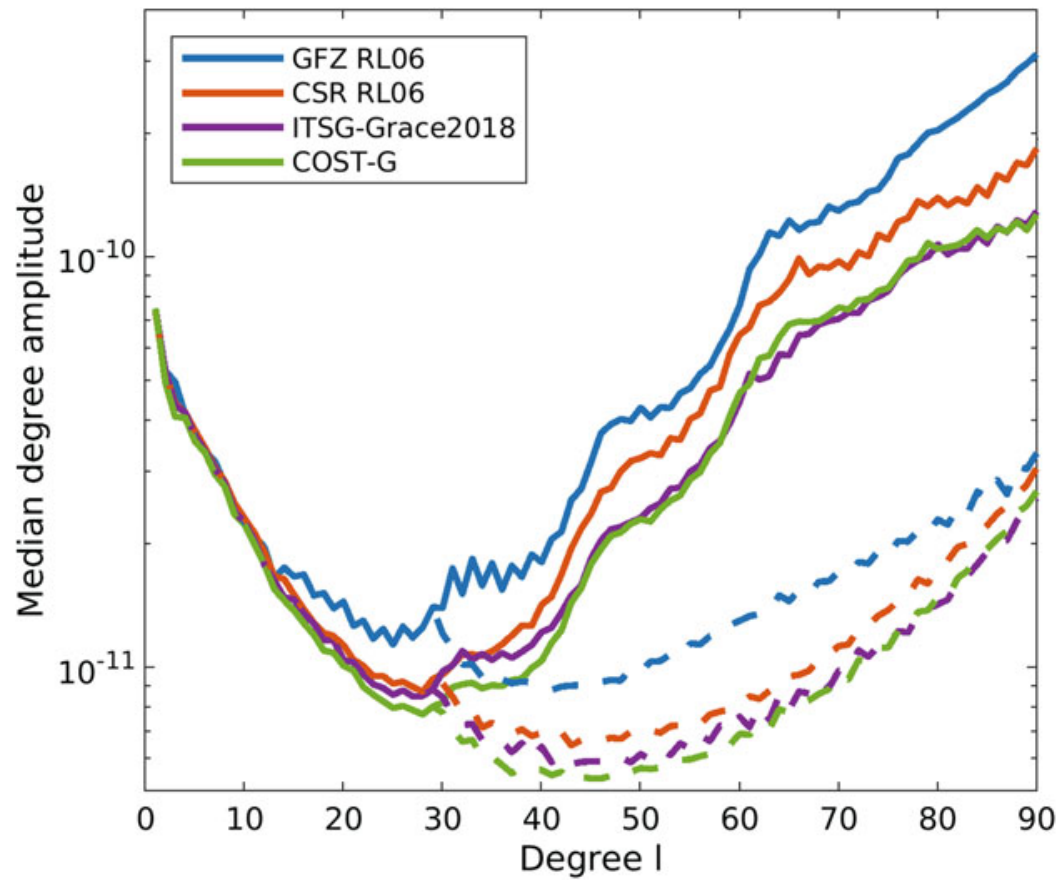

sensitivity kernel approach (Groh et al. 2019 and references in there).

The estimated linear trends of ice mass change for all drainage basins and for the entire Greenland ice sheet agree very well for the different solutions (not shown). Most notably the COST-G time series is characterized by a very favorable noise behavior. Figure 5 shows the noise levels of the mass change time series available over the entire time span in terms of the scaled standard deviation of the derived noise time series for all Greenland Ice Sheet drainage basins and the entire ice sheet following the method of Groh et al. (2019). For the majority of the basins the COST-G time series shows indeed the lowest noise of all solutions used for the combination.

\section{Antarctic lce Sheet}

A similar analysis is performed for the drainage basins of the Antarctic Ice Sheet (AIS, see footnote 3), selected aggregations, and for the entire Antarctic ice sheet. Whereas most of the results of this analysis confirm the level of agreement found for the Greenland Ice Sheet, the linear trends resulting for different gravity field solutions for some drainage basins deserve special attention. Figure 6 compiles for the solutions available over the entire time span the estimated linear trends and error bars in ice mass change for selected drainage basins, the Antarctic Peninsula, East Antarctica, West Antarctica, and for the entire ice sheet. The displayed error bars account for the formal errors of the estimated trends, as well as for leakage errors and errors in the applied model reductions.
Figure 6 shows that the trends resulting from all solutions agree fairly well for West Antarctica. It also reveals, however, that discrepancies are occurring for East Antarctica. Whereas the trends resulting from the CSR RL06 and the ITSGGrace2018 solutions are in almost perfect agreement, the GFZ RL06 solution suggests a different trend for this entire region. However, all trend estimates agree within their error estimates, since these are clearly dominated by the error of the reduced glacial isostatic adjustment model. As a consequence of the weighting scheme used for the combined solution, the trend of the COST-G solution is in-between the two concurring trends. Due to the larger weights assigned to the CSR / ITSG solution (cf. Fig. 3), it is closer to these solutions. Figure 6 also shows that the different trends over East Antarctica influence the trends resulting for the entire ice sheet. Trend analyses based on shorter time periods common to all solutions show again different trends for the AIUB RL02 and GRGS RL04 solutions (not shown).

\subsubsection{External Validation}

Currently two methods are realized within COST-G to assess the quality of the solutions by independent data sets. More external validations may follow in the future.

\section{Comparison to Altimetry}

Currently two test areas (Caspian Sea, Black Sea) are selected within COST-G for an independent signal assessment. The time series of the time-variable gravity field solutions are compared with the time series of altimetric heights, derived from Hydroweb for the Caspian Sea and 


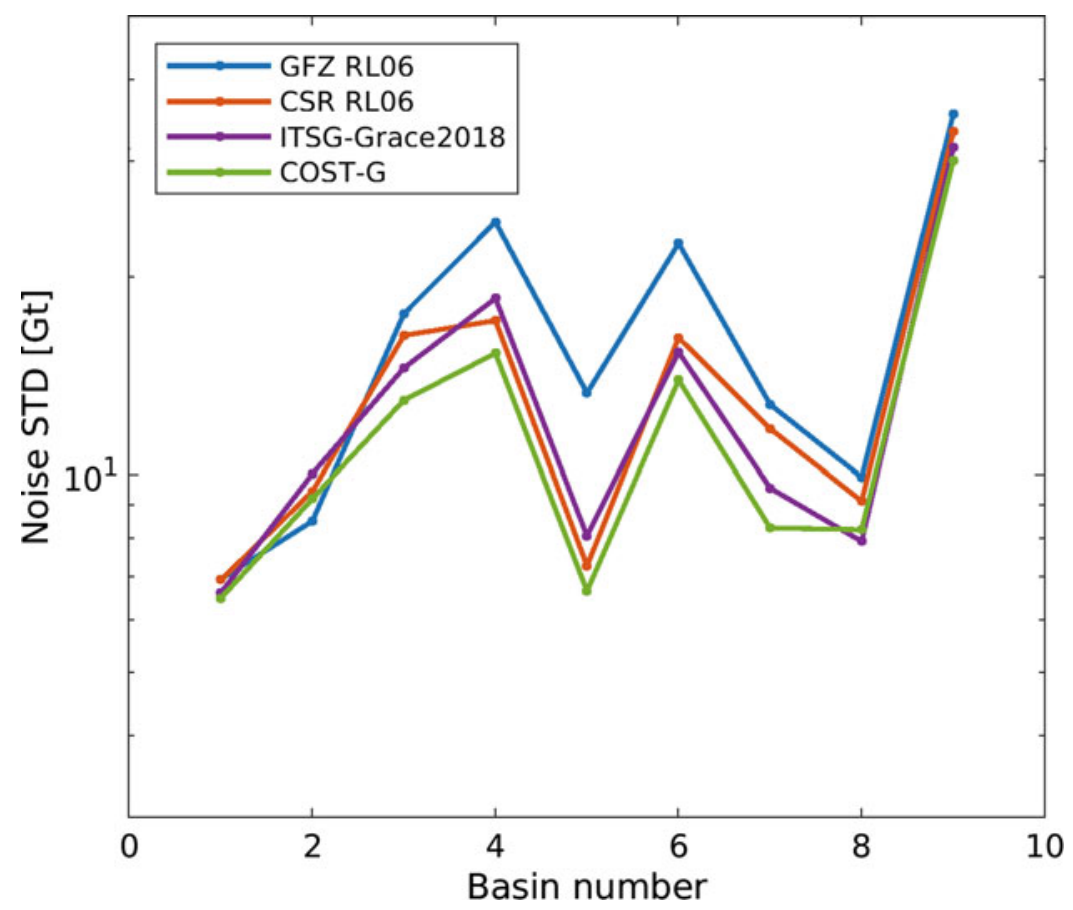

Fig. 5 Noise level of the mass change time series for all GIS basins and the entire GIS (basin no. 9)

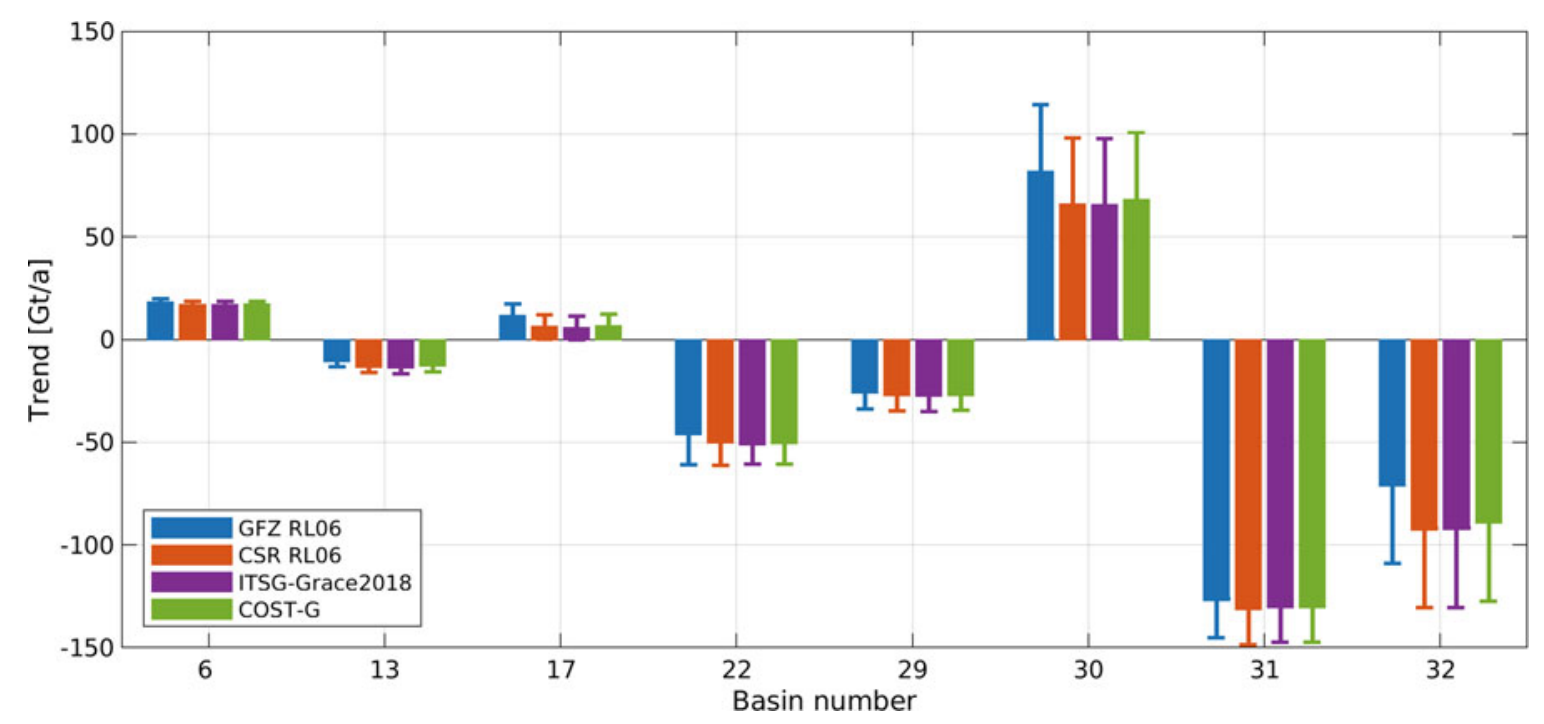

Fig. 6 Linear trend and error bars in ice mass for drainage basins of the AIS (6, 13, 17, 22), selected aggregations (29: Antarctic Peninsula, 30: East Antarctica, 31: West Antarctica) and the entire ice sheet (32) 
AVISO+ for the Black Sea. One bias and one scale factor are adjusted to perform the comparison.

Table 1 exemplarily shows the correlation coefficients over the Caspian Sea when filtering the gravity field solutions with different DDK filters (Kusche 2007). It can be seen that the COST-G solution presents in this metric a slight improvement with respect to the input solutions.

\section{Orbital Fits}

The long to medium wavelength accuracy of gravity field models can be evaluated through dynamic orbit computations as commonly done for the evaluation of static gravity fields, e.g. Gruber et al. (2011). In the frame of COST-G the same concept is adopted to the time-variable gravity field solutions from the individual ACs and thereof derived combined solution. In order to not suffer from large omission errors of the time-variable GRACE solutions, which are generally only available up to degree and order 90, all solutions are filled up to degree and order 240 with the $\mathrm{SH}$ coefficients of the GOCE static model DIR-6 (Förste et al. 2019). For the COST-G RL01 dynamic GOCE orbits with an arc length of 1.25 days were fitted to the GOCE kinematic precise science orbits (Bock et al. 2014) serving as pseudo-observations. The gravitational forces were modeled according to the different gravity field models under consideration, whereas non-gravitational accelerations were described by the highquality GOCE accelerometer data. For each arc three common mode acceleration biases are estimated in addition to the initial state vector. The scale factors of the common mode accelerations were fixed to one (Gruber et al. 2011).

Table 2 shows the RMS of orbit fits for the different test cases, derived as mean values from the $3 \mathrm{D}$ residuals from the 30/31 individual arcs under consideration for each month. It can be seen that the COST-G RL01 solution is also assessed in this metric of very good quality, but there is potential for further improvements as the solution is not yet best for each of the tested months. Note that the orbit test

Table 1 Correlation with altimetry over the Caspian Sea

\begin{tabular}{l|l|l|l}
\hline Filter & CSR RL06 & ITSG-Grace2018 & COST-G RL01 \\
\hline DDK5 & $96.6 \%$ & $97.0 \%$ & $97.2 \%$ \\
\hline DDK6 & $96.3 \%$ & $96.5 \%$ & $96.6 \%$ \\
\hline
\end{tabular}

Table 2 RMS of dynamic GOCE orbit fits $(\mathrm{cm})$ for the different gravity fields

\begin{tabular}{l|l|l|l|l}
\hline Gravity model & $2009 / 11$ & $2009 / 12$ & $2010 / 10$ & $2010 / 11$ \\
\hline GFZ RL06 & 7.4 & 6.8 & 6.2 & 6.2 \\
\hline AIUB RL02 & 8.7 & 8.6 & 7.4 & 7.2 \\
\hline CSR RL06 & 6.9 & 9.0 & 6.6 & 6.2 \\
\hline GRGS RL04 & 5.9 & 7.3 & 5.5 & 5.8 \\
\hline ITSG-Grace2018 & 5.5 & 5.1 & 4.2 & 4.5 \\
\hline COST-G RL01 & 5.0 & 5.5 & 4.5 & 4.7 \\
\hline
\end{tabular}

does not primarily validate $\mathrm{C} 20$ of the individual solutions. Only marginal differences would result if C20 is replaced in all solutions with one and the same value (not shown).

\section{Conclusions}

COST-G has officially started its operational service at the IUGG's 2019 General Assembly as a new Product Center of IAG's International Gravity Field Service (IGFS). It continues the scientific combination prototype service that has been established within the EGSIEM initiative to realize a longawaited standardization of gravity-derived mass transport products under the umbrella of the IAG. COST-G recognizes and emphasizes the existence and acknowledges the contribution of every individual analysis center and partner analysis center to this community effort. Their participation is a crucial and mandatory prerequisite to the consolidation of monthly global gravity fields within COST-G.

At the occasion of the 2019 IUGG General Assembly COST-G has provided a first release of combined GRACE monthly solutions covering the entire GRACE time period between April 2002 and June 2017 by combining the solutions of five contributing centers. In addition COST-G also provides combined Swarm monthly solutions as an operational product in the frame of an ESA initiative (Teixeira da Encarnação et al. 2019). Depending on the interest of the scientific community, further products may be established in the future, e.g. combined monthly solutions derived from SLR satellites. For GRACE and GRACE-FO it is planned to base future COST-G releases whenever possible on the combination of the normal equations of the underlying input solutions.

COST-G has set up a workflow that allows for a rigorous evaluation of the products by both internal and external means. The experience from the first release of combined monthly GRACE solutions has underlined that such a rigorous evaluation is of key importance to ensure the quality of the COST-G products and will therefore be further extended in the future. Although the COST-G RL01 solutions show an excellent behavior in terms of noise, as it is demonstrated by the various internal and external quality metrics, a discrepancy in the signal has been revealed by the COST$G$ product evaluation group for the different input solutions when regarding ice mass trends over East Antarctica. As this also affects the trends of the COST-G RL01 for that region, the root cause is currently being further investigated. The COST-G workflow also includes the generation of Level2B products to derive thereof user-friendly Level-3 products that will enable hydrologists, glaciologists, oceanographers, geodesists and geophysicists to fully profit from one combined, and consolidated monthly GRACE gravity product. Updates will be announced at http://cost-g.org. 
Acknowledgements This article is dedicated to Richard Biancale, who unexpectedly passed away on February 4, 2019. His support and promotion of the activities described in this article are gratefully acknowledged. The study was performed in the framework of an international team, led by Richard Biancale and the first author of this article, that is receiving support from the International Space Science Institute (ISSI) in Bern, Switzerland.

\section{References}

Bock H, Jäggi A, Beutler G et al (2014) GOCE: precise orbit determination for the entire mission. J Geod 88(11):1047-1060. https://doi. org/10.1007/s00190-014-0742-8

Dahle C, Murböck M, Flechtner F et al (2019) The GFZ GRACE RL06 monthly gravity field time series: processing details and quality assessment. Remote Sens 11:2116. https://doi.org/10.3390/ rs11182116

Drewes H, Kuglitsch F, Ádám J (2016) The geodesist's handbook 2016. J Geod 90(10):907-1205

Flechtner F, Morton P, Watkins M et al (2013) Status of the GRACE follow-on mission. In: Marti U (ed) Gravity, geoid and height systems. IAG symposia, pp 117-121. https://doi.org/10.1007/978-3319-10837-7_15

Förste C, Abrykosov O, Bruinsma S et al (2019) ESA's Release 6 GOCE gravity field model by means of the direct approach based on improved filtering of the reprocessed gradients of the entire mission. GFZ Data Services. https://doi.org/10.5880/ICGEM.2019.004

GRACE Level 1B JPL Release 3.0 (2018) Ver. 3. PO.DAAC, CA, USA. https://doi.org/10.5067/GRJPL-L1B03

Groh A, Horwath M, Horvath A et al (2019) Evaluating GRACE mass change time series for the Antarctic and Greenland Ice Sheet - methods and results. Geosciences 9:415. https://doi.org/10.3390/ geosciences9100415

Gruber T, Visser PNAM, Ackermann C et al (2011) Validation of GOCE gravity field models by means of orbit residuals and geoid comparisons. J Geod 85(11):845-860. https://doi.org/10.1007/s00190-0110486-7

Ince ES, Barthelmes F, Reissland S et al (2019) ICGEM - 15 years of successful collection and distribution of global gravitational models, associated services, and future plans. Earth Syst Sci Data 11:647674

Jäggi A, Weigelt M, Flechtner F et al (2019) European Gravity Service for Improved Emergency Management (EGSIEM) - from concept to implementation. Geophys J Int 218(3):1572-1590. https://doi.org/ $10.1093 /$ gji/ggz238
Jean Y, Meyer U, Jäggi A (2018) Combination of GRACE monthly gravity field solutions from different processing strategies. J Geod 92(11):1313-1328. https://doi.org/10.1007/s00190-018-1123-5

Klinger B, Mayer-Gürr T (2016) The role of accelerometer data calibration within GRACE gravity field recovery: results from ITSGGrace2016. Adv Space Res 58(9):1597-1609. https://doi.org/10. 1016/j.asr.2016.08.007

Kusche J (2007) Approximate decorrelation and non-isotropic smoothing of time-variable GRACE-type gravity field models. J Geod 81(11):733-749. https://doi.org/10.1007/s00190-007-0143-3

Kvas A, Behzadpour S, Ellmer M et al (2019) ITSG-Grace2018: overview and evaluation of a new GRACE-only gravity field time series. J Geophys Res Solid Earth 124:9332. https://doi.org/10.1029/ 2019JB017415

Meyer U, Jäggi A, Beutler G et al (2015) The impact of common versus separate estimation of orbit parameters on GRACE gravity field solutions. J Geod 89(7):685-696. https://doi.org/10.1007/s00190015-0807-3

Meyer U, Jäggi A, Jean Y et al (2016) AIUB-RL02: an improved timeseries of monthly gravity fields from GRACE data. Geophys J Int 205(2):1196-1207. https://doi.org/10.1093/gji/ggw081

Meyer U, Jean Y, Kvas A et al (2019) Combination of GRACE monthly gravity fields on the normal equation level. J Geod 93:1645-1658. https://doi.org/10.1007/s00190-019-01274-6

Save H, Tapley B, Bettadpur S et al (2018) GRACE RL06 reprocessing and results from CSR, presented at EGU 2018, abstract EGU201810697

Shepherd A, Ivins ER, Geruo A et al (2012) A reconciled estimate of ice-sheet mass balance. Science 338:1183-1189. https://doi.org/10. 1126/science. 1228102

Tapley B, Flechtner F, Watkins M et al (2015) GRACE mission: status and prospects. Presented at: Grace science team meeting, Austin, Texas. https://doi.org/10.1038/s41558-019-0456-2

Tapley BD, Watkins MM, Flechtner F et al (2019) Contributions of GRACE to understanding climate change. Nat Clim Change 9:358369

Teixeira da Encarnação J, Visser P, Arnold D et al (2019) Multiapproach gravity field models from Swarm GPS data. Earth Syst Sci Data. In press. https://doi.org/10.5194/essd-2019-158

Wahr J, Nerem RS, Bettadpur SV (2015) The pole tide and its effect on GRACE time-variable gravity measurements: implications for estimates of surface mass variations. J Geophys Res Solid Earth 120:4597-4615. https://doi.org/10.1002/2015JB011986

Open Access This chapter is licensed under the terms of the Creative Commons Attribution 4.0 International License (http://creativecommons. org/licenses/by/4.0/), which permits use, sharing, adaptation, distribution and reproduction in any medium or format, as long as you give appropriate credit to the original author(s) and the source, provide a link to the Creative Commons licence and indicate if changes were made.

The images or other third party material in this chapter are included in the chapter's Creative Commons licence, unless indicated otherwise in a credit line to the material. If material is not included in the chapter's Creative Commons licence and your intended use is not permitted by statutory regulation or exceeds the permitted use, you will need to obtain permission directly from the copyright holder.

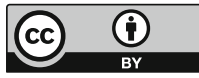

